\title{
The focal takotsubo syndrome presenting with the snail-like left ventricle
}

\author{
Alicja Genc®, Jakub Sobolewski, Witold Bachorski, \\ Izabela Pisowodzka, Miłosz Jaguszewski, Marcin Fijałkowski \\ First Department of Cardiology, Medical University of Gdansk, Poland \\ This paper was guest edited by Prof. Anna Tomaszuk-Kazberuk
}

Focal takotsubo syndrome (TTS) is a rare, atypical type of TTS reported in 2004 as anterior akinesis of the left ventricle (LV) with no coronary changes. Based on the International Takotsubo Registry, it occurs in about $1.5 \%$ of cases. To date, this uncommon form has not been called anything other than "focal". Typical left ventricular apical ballooning resembled a takotsubo (jap. tako - octopus, $t$ subo - pot), hence the then-novel disease was named after it. In our observation, the LV in focal TTS can resemble a snail in imaging studies.

A 70-year-old female was referred to the hospital due to severe angina. It started 2 days before admission caused by severe emotional distress. The electrocardiogram showed ST-segment elevation in leads II, III, and aVF, with a QTc interval of $454 \mathrm{~ms}$, a heart rate of $74 \mathrm{bpm}$ and increased high sensitivity troponin I levels $(3.4 \mathrm{ng} / \mathrm{mL})$, while the maximum B-type natriuretic pep- tide concentration did not exceed $120 \mathrm{pg} / \mathrm{mL}$. Vital signs remained stable. The patient was subsequently qualified for urgent cardiac catheterization, which revealed no obstructive coronary artery disease and akinesis of the mid-anterior heart segment on ventriculography. The LV shape during systole resembled a snail (Fig. 1A, B, Suppl. Video 1). Echocardiography confirmed the presence of $\mathrm{LV}$ anterior wall akinesis (Fig. 1C, D), which was visualized objectively with longitudinal strain (Fig. 1E). However, the echo abnormalities were transient - a feature typical for TTS. The patient remained asymptomatic and was discharged home on the $6^{\text {th }}$ day of hospitalization. Contractile disfunction was not observed after a 5-week follow-up.

In such cases, even if the initial imaging is not typical for TTS (snail-like image) and clinical suspicion is high, TTS should not be excluded.

Conflict of interest: None declared

Address for correspondence: Alicja Genc, MD, First Department of Cardiology, Medical University of Gdansk, ul. Dębinki 7, 80-952 Gdańsk, Poland, tel: +48 5834925 00, fax: +48 5834612 01, e-mail: alicja.genc@gumed.edu.pl

This article is available in open access under Creative Common Attribution-Non-Commercial-No Derivatives 4.0 International (CC BY-NC-ND 4.0) license, allowing to download articles and share them with others as long as they credit the authors and the publisher, but without permission to change them in any way or use them commercially. 


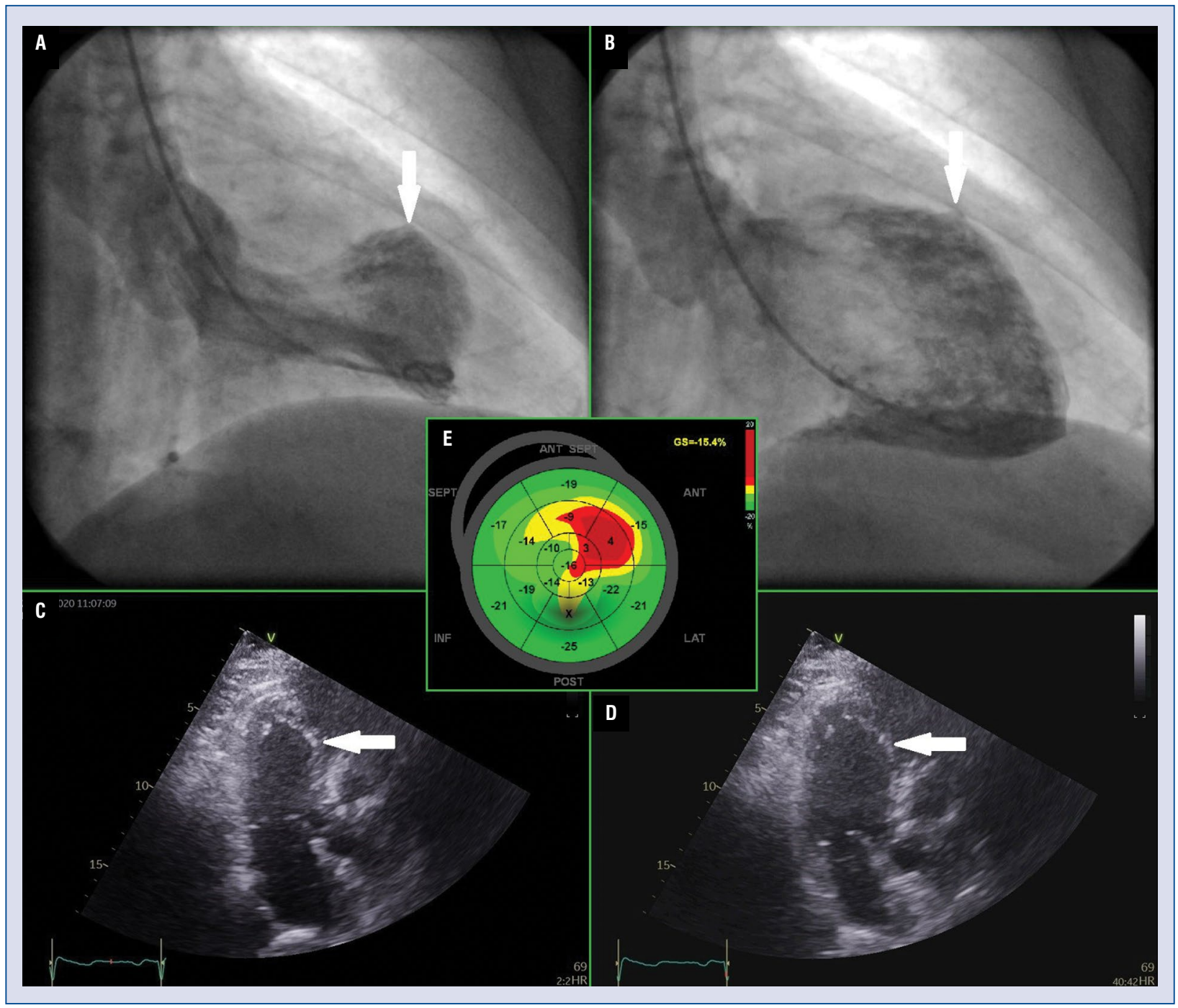

Figure 1. Ventriculography showing the snail-like shape of left ventricle (LV) and focal akinesis of its anterior wall in systole (A) and LV in diastole (B). The same regional wall motion abnormalities were observed in echocardiography during systole (C) and in diastole (D). White arrows mark the akinetic segment. Display of regional longitudinal strain (Bull's Eye Plot) showed abnormal LV longitudinal strain, systolic lengthening of mid anterolateral segment (E). 